\title{
Evaluation of Driver Distraction with Changes in Gaze Direction Based on a Vestibulo-Ocular Reflex Model
}

\author{
Le Anh Son', Hirofumi Aoki², Tatsuya Suzuki ${ }^{1}$ \\ ${ }^{1}$ Graduate School of Engineering, Nagoya University, Nagoya, Japan \\ ${ }^{2}$ Institute of Innovation for Future Society, Nagoya University, Nagoya, Japan \\ Email: leanhsonvn@gmail.com, le.anh.son@b.mbox.nagoya-u.ac.jp
}

How to cite this paper: Son, L.A., Aoki, H. and Suzuki, T. (2017) Evaluation of Driver Distraction with Changes in Gaze Direction Based on a Vestibulo-Ocular Reflex Model. Journal of Transportation Technologies, 7 , 336-350.

https://doi.org/10.4236/jtts.2017.73022

Received: May 11, 2017

Accepted: July 21, 2017

Published: July 24, 2017

Copyright $\odot 2017$ by authors and Scientific Research Publishing Inc. This work is licensed under the Creative Commons Attribution International License (CC BY 4.0).

http://creativecommons.org/licenses/by/4.0/

\begin{abstract}
With the aim of improving parameter identification and, eventually, evaluating driver distraction with changes in gaze direction, we applied a genetic algorithm (GA) method to identify parameters for an existing vestibulo-ocular reflex (VOR) model. By changing the initial inputs to the GA and fixing two parameters pertaining to the horizontal direction, we achieved improved parameter identification with a lower mean-square error. The influence of driver distraction on eye movement with changes in gaze direction was evaluated from the difference between the predicted and observed VOR in the vertical axis. When a driver was given an additional mental workload, the mean-square error between the measured and simulated values was bigger than that in the absence of the mental workload. This confirmed the relationship between driver distraction and eye movement in the vertical direction. We hope that this method can be applied in evaluating driver distraction.
\end{abstract}

\section{Keywords}

Vestibulo-Ocular Reflex Model (VOR), Optokinetic Reflex (VOR), Mental Workload, Drive Distraction

\section{Introduction}

\subsection{The Vestibulo-Ocular Reflex Model and Its Application}

The vestibular system, which is a sensory mechanism in the inner ear, provides the principal contribution to the sense of balance and spatial orientation. The system consists of two parts: the otoliths and the semicircular canals. The former have two main functions: detection of linear motions of the head, and detection of the head's position relative to the force of gravity. The semicircular canals 
consist of three canals in each ear: the horizontal, anterior, and posterior canals; the horizontal canal detects angular accelerations of the head, whereas the anterior and posterior canals detect vertical movements. Previous researches have shown that movements of the eye can be estimated from movements of the head [1] [2].

When the head is turned to the left, the eyes move in the opposite direction to stabilize the visual world based on the input to the vestibular organ. This vestibule-ocular reflex (VOR) is a reflex eye movement that can be used to estimate eye movements from movements of the head. VOR models have been proposed by several researchers and have been used in various applications. In this research, we used the VOR model proposed by [1], which reflects interactions between the otoliths and the semicircular canals. In this model, head movement is represented by a linear acceleration and an angular velocity as inputs, and the movement of the eyeball is the output [2] (Figure 1).

Because the Merfeld and Zupan model has only first-order lag characteristics for the eye muscle, we combined it with Robinson's model as a final common-path segment. In total, our model contains four parameters to compensate for individual differences in VOR characteristics, and two parameters to compensate for individual differences in eye muscle characteristics.

This model has been used by other researchers to examine various aspects of driver behavior. For example, Omura et al. (2014) used the VOR model to determine the relationship between measured eye movements and subjective eval-

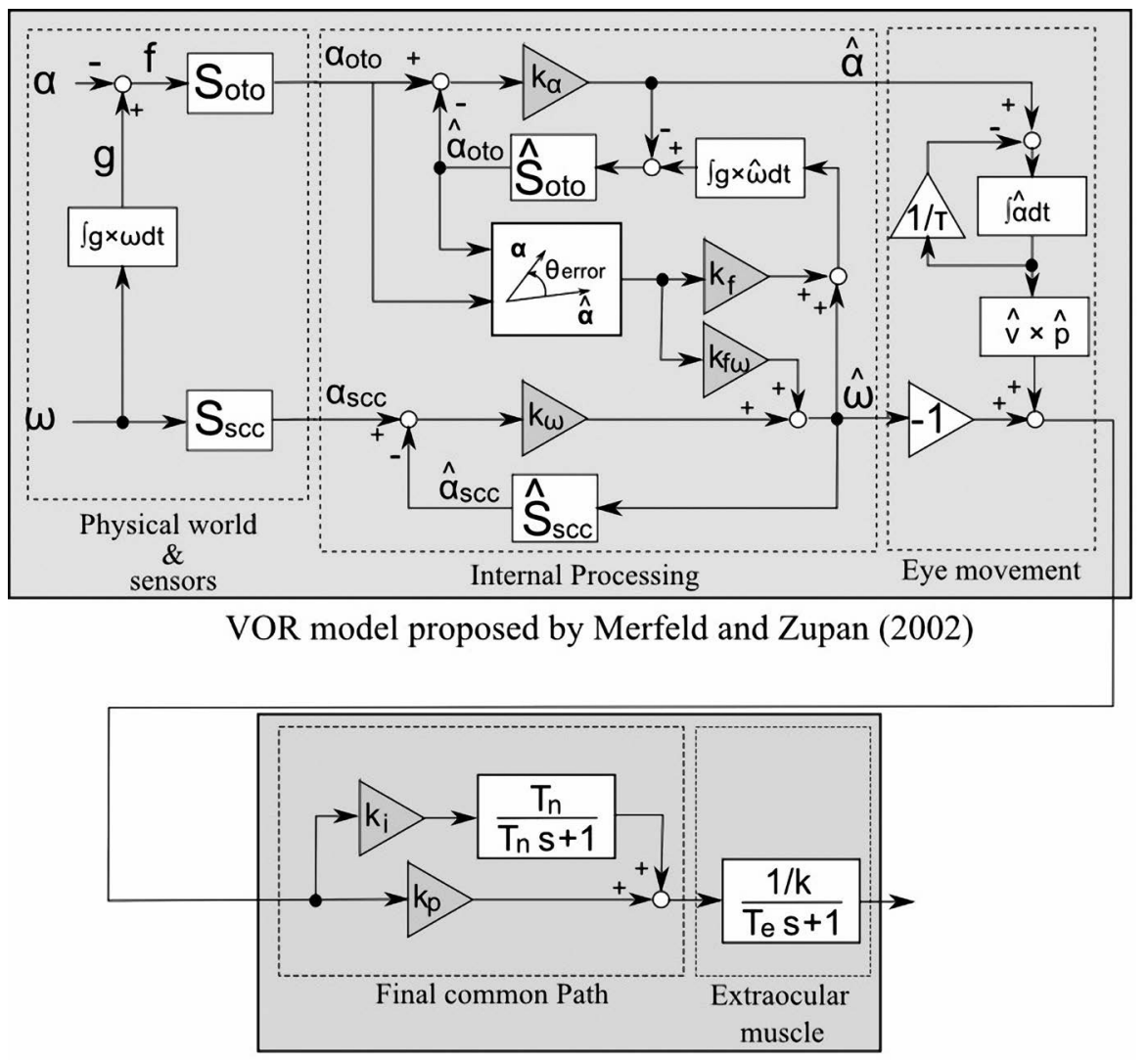

Final Common path part proposed by Robinson (1981)

Figure 1. VOR models. 
uations of simulated brake motion. In their research, the passenger's comfort was measured by comparing the observed eye movement with that simulated by using the VOR model. The researchers found a tendency toward a relationship, but the number of subject was insufficient for the purpose of making a decision. In addition, their parameter identification by using a hybrid genetic algorithm left a gap between simulation and measurement. Obinata's group has also used the VOR model to evaluate mental workload [3] and driver distraction in terms of memory-decision workload [4]. They presented a new method for quantifying mental workloads by utilizing the VOR. They did not, however, consider changes in gaze direction.

In the case of seated drivers controlling a steering wheel, the head movement has three axes of translation and rotation in the Cartesian coordinate system. However, Obinata et al. have stated that the horizontal axis has a much narrower range of movements than the vertical axis [3]. Consequently, we only considered movements in vertical direction, which have a strong effect on eye movement.

\subsection{Parameter Identification for the VOR Model}

Currently several methods have been proposed for identifying good parameters for a model; these include brute-force search, the Nelder-Mead simplex method, the trust region method, and the Gauss-Newton method [5]. Another successful method is the genetic algorithm (GA) method, which is based on Darwinian evolutionary principles: the mechanics of natural genetics (Goldberg, 1989). This method has been applied in a variety of areas, particularly for parameter estimations [6] [7] [8] [9]. The GA is a suitable method for optimization of nonlinear problem by determining global optimal solutions through natural selection and genetics.

For VOR parameters, Obinata et al. used a hybrid GA method to identify [10] [11] [12]. In these cases, eight parameters from Merfeld and Robinson's studies were examined simultaneously, with Merfeld and Zupan parameters as initial values. However, because of the wide range of each parameter, results after 100 generations were still not consistent with the measured values. The mean-square error increased as the time for one simulation or one experiment increased. Furthermore, the mean-square error also increased with increasing number of changes in gaze direction.

We therefore needed to improve the accuracy of the parameters in our research. To do this, in this study, we applied the technique of Son et al. (2015) to enhance the GA by generating near-optimal initial populations [13] to determine the range of each parameter and by changing the population size and relative elitism [14] [15]. In addition, an improved method was applied for parameter identification to permit the evaluation of driver distraction with changes in gaze direction.

\subsection{Objective}

Because the difficult of simulating eye movement with changing the gaze, the evaluation driver cognitive distraction became challenged in the past. Therefore, 
in this study, by improving the parameter identification method, the eye will be simulated and used to evaluate the driver distraction in case of changing gaze.

To do that, in this research, we had two main objectives:

- To improve parameter identification by updating the range of each parameter, based on the results of [15] and to fix two parameters pertaining to the horizontal direction; and

- To estimate mental workload on the basis of the difference between the predicted and actual eye movements.

In this research, we used the gap between the observed VOR responses and those predicted by the mathematical model as a measure of performance.

\section{Method}

\subsection{The Vestibulo-Ocular Reflex Model}

The main purpose of the VOR model is stabilizes images on retina during head movement by producing an eye velocity that is equal and opposite to head velocity. Figure 2 shows schematically how the VOR works during a horizontal head movement.

According to the results obtained by Zupan and Merfeld [16] and by Angelaki and co-workers [17] [18] [19], the transformation of a vestibular signal into internal-motion parameters involves two main computations. In the first, angular-velocity signals from the semicircular canals $(\omega)$ are used to segregate the resultant linear acceleration signals coded by primary otolith afferents $(\alpha)$ into

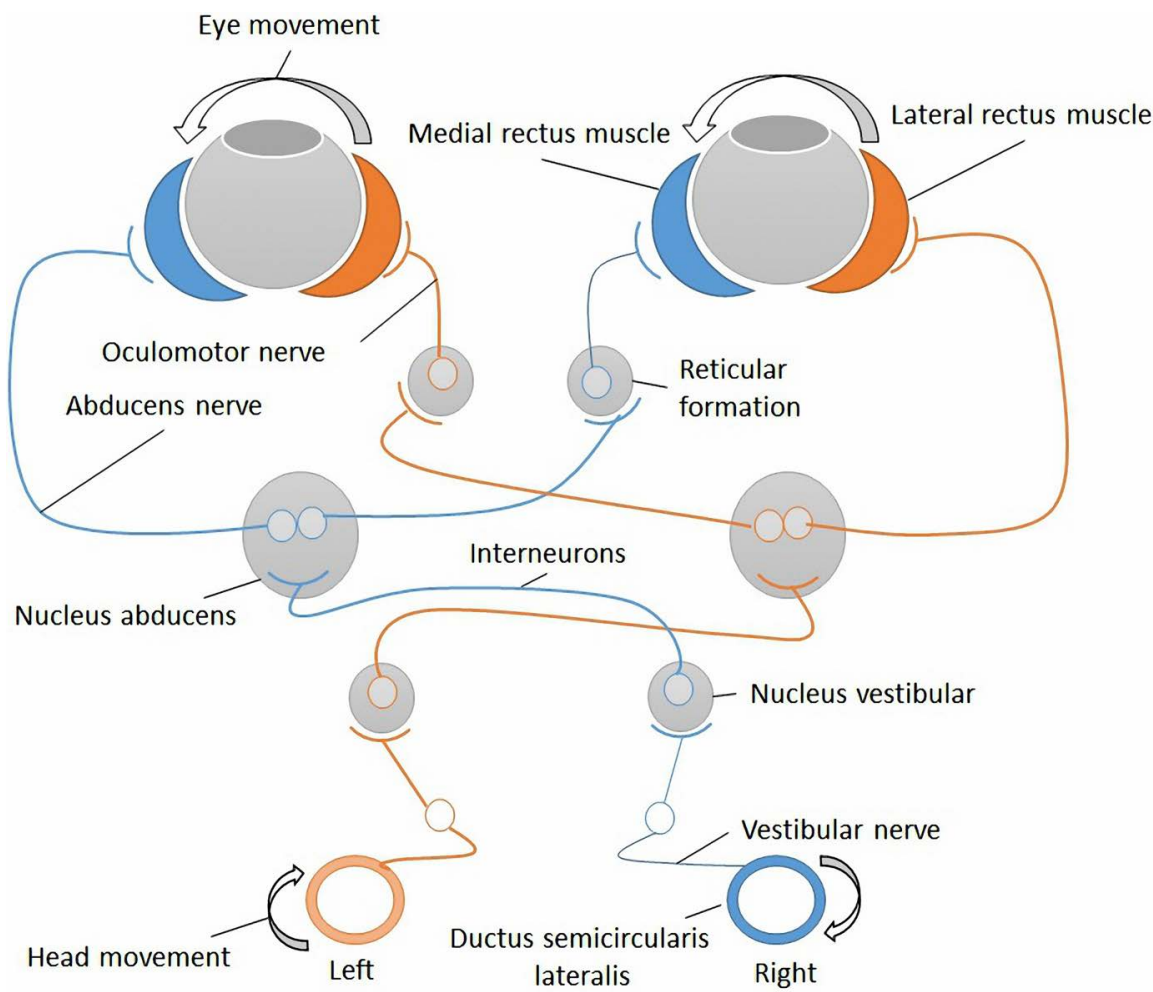

Figure 2. Schematic illustration of the three neural arc reflex of VOR (Source: https://en.wikipedia.org/wiki/Vestibulo\%E2\%80\%93ocular_reflex). 
gravitational (g, orientation) and translational (f) components. In the second, gravitational estimates are used to transform head-fixed angular-velocity signals from the semicircular canals $(\omega)$ to the inertial velocity, i.e., the space-referenced angular velocity $(\omega \mathrm{S})$.

Figure 3 shows the detailed blocks of the VOR model. The semicircular canals [which measure the angular velocity of the head $(\omega)$ ] and the otolith organs [which measure linear accelerations of the head $(\alpha)$ and gravity $(\mathrm{g})$ ] sense the proprioceptive information from the environment; this is the first step in calculating sensory information from the measurements $\left(\alpha_{\text {oto }}, \alpha_{\mathrm{scc}}\right)$. In the next step, the measurements are compared with the sensory information predicted by the internal model. This model combines four free parameters $\left(k_{\omega}, k_{f \omega}, k_{f}\right.$ and $\left.k_{a}\right)$. The parameters values were determined by the feedback of this error.

Because we're only considered with the head and eye movements in the vertical direction, the two parameters for the horizontal gain ( $p_{\text {kshor }}$ and $p_{\text {krhor }}$ ) remained constant.

After calculating the eye movement, the final common path proposed by [2] was applied. In this part, two parameters $\left(k_{i}, k_{p}\right)$ were used, based on the different types of muscle fibers present in muscles of the eye (Figure 4).

\subsection{Experimental Setup}

\section{- Parameter Identification}

In the experiment, a subject was asked to sit on the seat of a driving simulator with six degrees of freedom. The driving simulator had a cylindrical $360^{\circ}$ screen $6 \mathrm{~m}$ in diameter. The simulator was controlled by CarSim (Mechanical Simula-

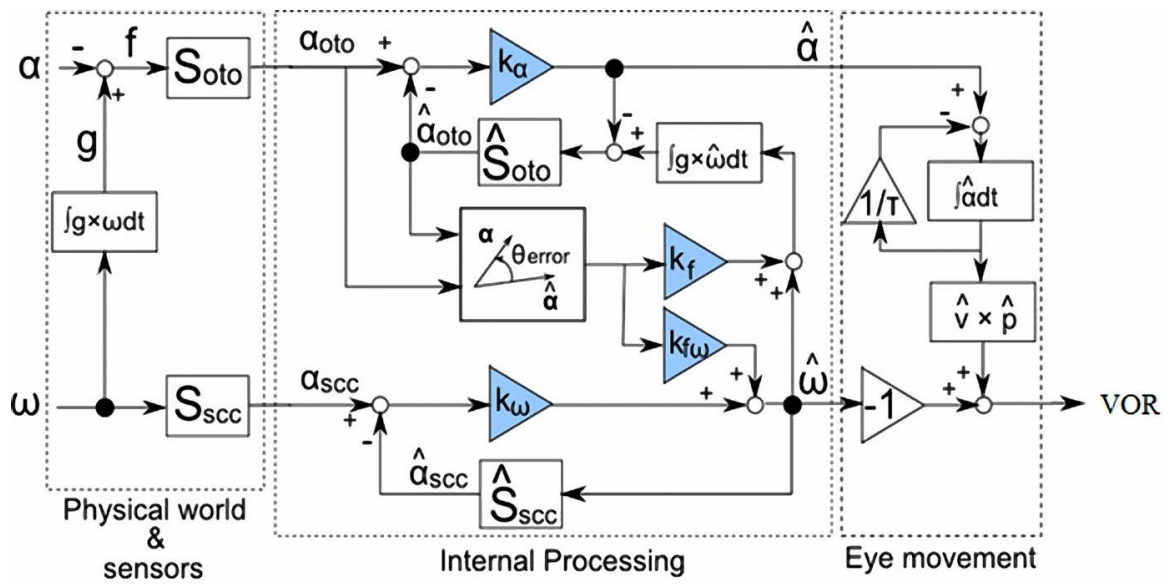

Figure 3. VOR model in MATLAB Simulink (MATLAB 2015b Pro Version 8.6 was used).

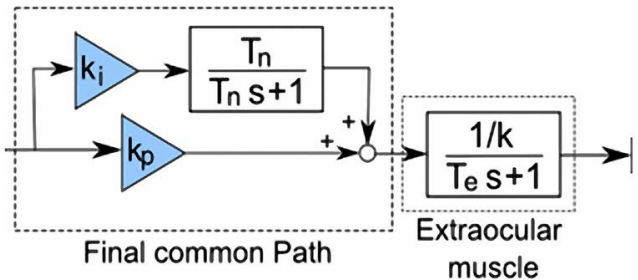

Figure 4. Visual target positions. 
tion Co.) which can simulate the dynamic behavior of a vehicle (Figure 5). By using MATLAB Simulink (MathWorks) to control CarSim, the seat was moved with a fixed frequency in the vertical plane, as in previous experiments.

We measured eye movements by using SmartEye Pro (Smart Eye AB) with four cameras on the simulator. This equipment is noninvasive, simple to install, and provides data by using a camera recorder. To collect information on movements of the head, we used a Fastrak electromagnetic tracker (Polhemus Inc.).

A total of 15 subjects who drive on a regular basis participated in the experiment to test the parameter-identification method. During the parameter-identification phase, the participant was seated in the car simulator and looked straight ahead for $10 \mathrm{~s}$ without changing their gaze. The seat movements were be controlled by CarSim and were identical for each individual.

\section{- Driver distraction}

Subsequently, we conducted an experiment to examine the effect of mental workload on eye movement. The gaze movement was as shown below (Figure 6).

In this case, CarSim produced identical movements of the car seat in all the

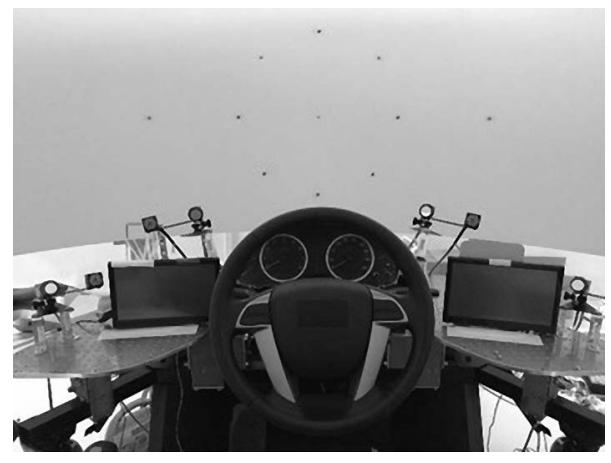

Figure 5. Overview of the experimental setup.

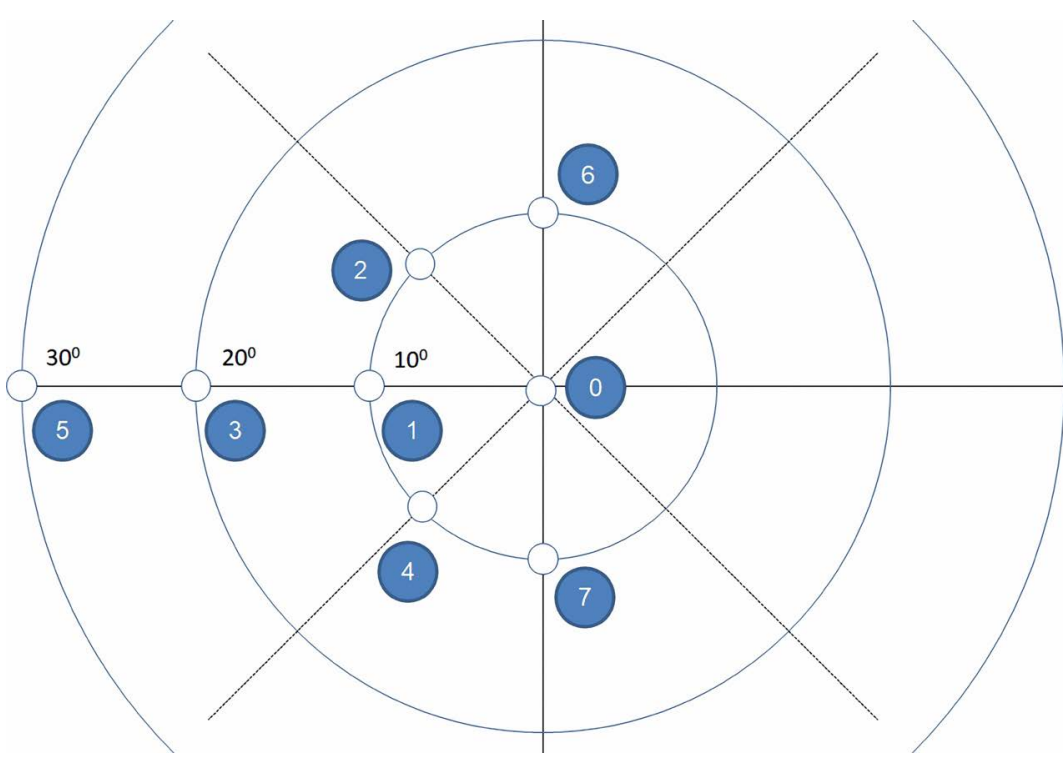

Target order: $\rightarrow$ (1) $\rightarrow \rightarrow$ (2) $\rightarrow \rightarrow$ (3) $\rightarrow \rightarrow$ (4) $\rightarrow \rightarrow$ (5) $\rightarrow \rightarrow$ (6) $\rightarrow \rightarrow$ (7) $\rightarrow$;

With time: $10 \mathrm{~s} \rightarrow 5 \mathrm{~s} \rightarrow 5 \mathrm{~s} \rightarrow 5 \mathrm{~s} \rightarrow 5 \mathrm{~s} \rightarrow 5 \mathrm{~s} \rightarrow 5 \mathrm{~s} \rightarrow 5 \mathrm{~s} \rightarrow 5 \mathrm{~s} \rightarrow 5 \mathrm{~s} \rightarrow 5 \mathrm{~s} \rightarrow 5 \mathrm{~s} \rightarrow 5 \mathrm{~s} \rightarrow 5 \mathrm{~s} \rightarrow 10 \mathrm{~s}$

Figure 6. Visual target positions. 
experiments, each consisting of two different sine waves. Subjects seated on the chair changed their gaze to comply with instructions.

An n-back task was used to evaluate distraction. In the n-back task, a series of one-digit numbers is presented verbally to the subject. The subject is then asked to answer by pressing a button on the steering wheel when the current number matches the number given $n$ steps earlier in the sequence. In this study, $n=1$ and the interval between two successive numbers was $2 \mathrm{~s}$.

A total of 15 subjects participated (two trials per subject); the subjects had different individual characteristics.

\section{Results and Discussions}

\subsection{Parameters Identification}

Data from 15 subjects who drive every day were collected for parameter identification. The collected data were subjected to a cleaning process and subsequently used in parameter identification, according to the method proposed by Son et al. (2015). The result of parameter identification showed a good performance with an average mean-square error of 3.09E-04; the maximum meansquare error was 6.13E-04 and the minimum was 6.12E-05 (Figure 7).

By changing the initial input of the GA and fixing two parameters in final common-path part (p_kshor and p_krhor), the result of parameters identification by using Fastrak and SmartEye Pro in this experiment produced a better performance than motion capture (MAC3D) or the eye tracker (T.K.K.2930a, Takei Scientific Instruments Co., Ltd.) [15]. The average of the mean-square errors was reduced from $1.26 \mathrm{E}-03$ to $3.09 \mathrm{E}-04$. The maximum and minimum values of the mean-square error were also lower than the previous ones; in the study by Son et al., the maximum was $4.4 \mathrm{E}-03$ and the minimum was $6.5 \mathrm{E}-05$, whereas in the current study, the maximum mean-square error was $6.13 \mathrm{E}-04$ and the minimum was $6.12 \mathrm{E}-05$.

Figure 8 shows the eye movements in the vertical axis for Subject 2. The red line is the measured eye movement and the blue line is the simulation. The results shown in Figure 8 confirm that the identification produces good matches in time responses and frequency responses. This means that our method is ap-

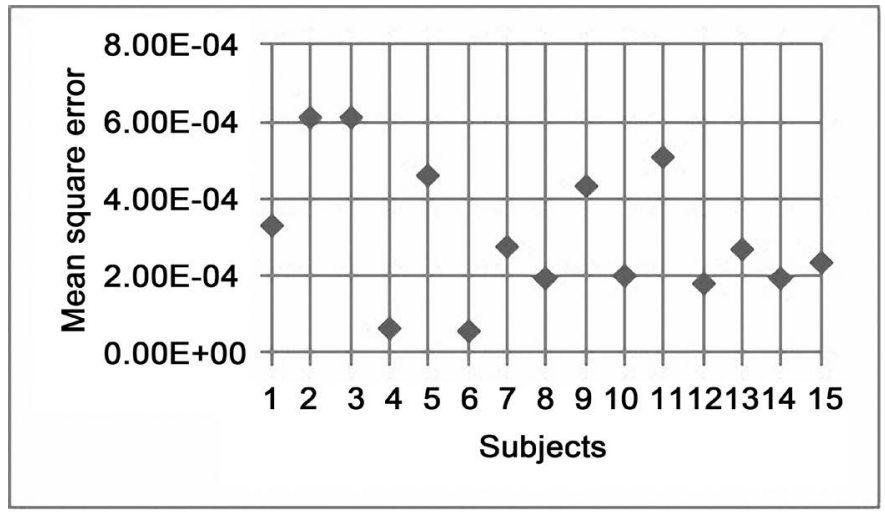

Figure 7. Mean square error of parameter identification. 


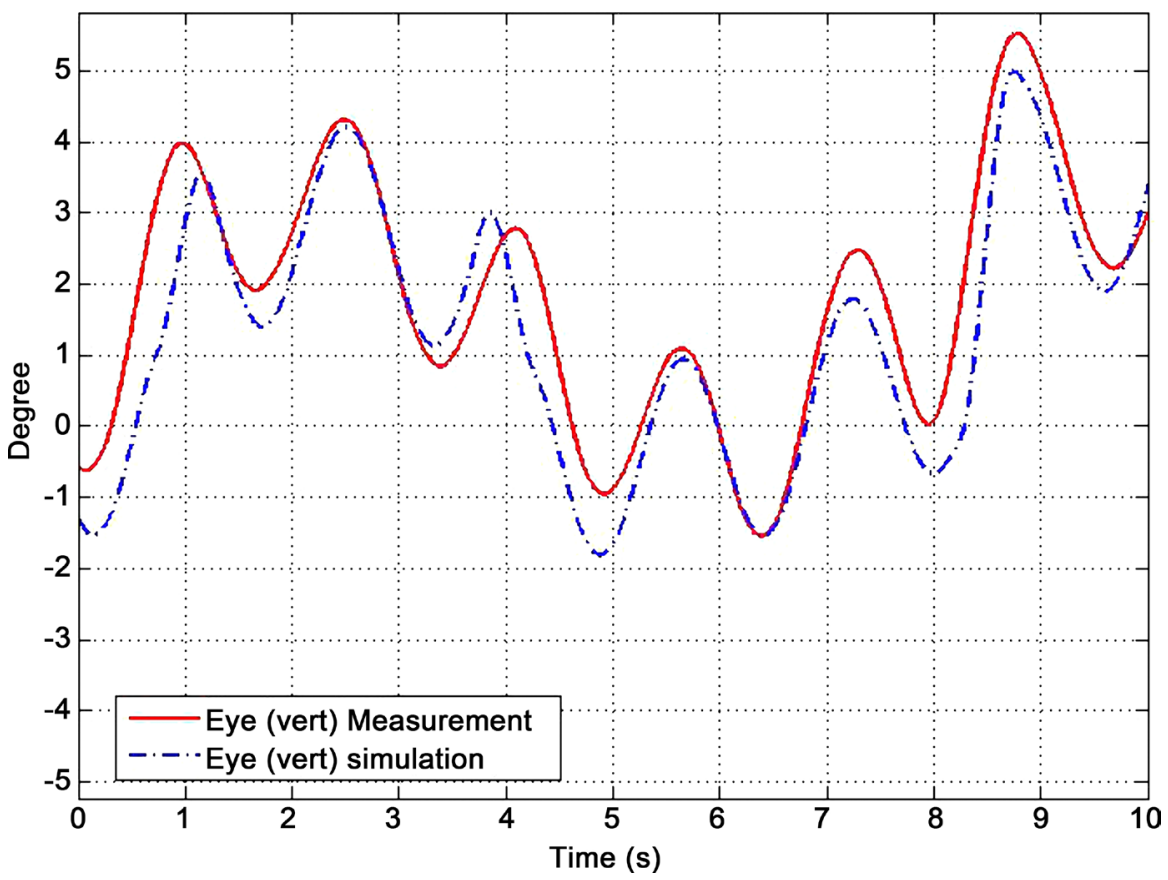

Figure 8. Eye movement in the vertical axis for subject 2 .

plicable to experiments with SmartEye and Polhemus.

\subsection{Parameters Identification for the Driver Distraction Experiment}

As reported by Obinata et al. and others [3] [4] [15] [17], motion sickness has a strong effect on VOR parameters. To identify the optimal VOR parameters for driver distraction, we used the first ten seconds in our distraction-evaluation experiment for parameter identification, and then we applied the identified parameters throughout the remainder of the experiments.

The results of parameter identification for each subject in the driver-distraction experiment showed good performance, with a low mean-square error (Table 1). The range of mean-square errors was $1.59 \mathrm{E}-04$ to $5.96 \mathrm{E}-04$, with an average of 3.23E-04. The time and the frequency responses also matched well (Figure 9).

We conducted our experiments as follows. First, the participant was asked to gaze steadily at the target for $10 \mathrm{~s}$ to permit parameter identification. We then used the results of the parameter identification to simulate the second part of the experiment, in which the subject changed their case sequentially according to instructions. The results of the final simulation measurements are shown in Figure 10.

As can be seen in Figure 10, for the eye movement in the vertical axis of Subject 2, the new parameters showed a good performance with a mean-square error of $9.25 \mathrm{E}-04$. Conversely, the parameters proposed by Merfeld and Zupan (2002) were poor in terms of both the trend and value, and the mean-square error in this case was very high (7.33), more than 7000 times larger than that achieved with our new set of parameters. Similar results were obtained with the other subjects. 
Table 1. Mean-square error in parameter identification for each subject.

\begin{tabular}{cc}
\hline Subjects & Mean square error \\
\hline 1 & $5.96 \mathrm{E}-04$ \\
3 & $3.00 \mathrm{E}-04$ \\
4 & $4.59 \mathrm{E}-04$ \\
$\mathbf{5}$ & $4.19 \mathrm{E}-04$ \\
6 & $3.90 \mathrm{E}-04$ \\
7 & $4.25 \mathrm{E}-04$ \\
8 & $1.98 \mathrm{E}-04$ \\
9 & $2.75 \mathrm{E}-04$ \\
10 & $2.18 \mathrm{E}-04$ \\
11 & $1.59 \mathrm{E}-04$ \\
12 & $2.31 \mathrm{E}-04$ \\
13 & $1.85 \mathrm{E}-04$ \\
14 & $4.37 \mathrm{E}-04$ \\
15 & $3.95 \mathrm{E}-04$ \\
\hline & $1.68 \mathrm{E}-04$ \\
\hline
\end{tabular}

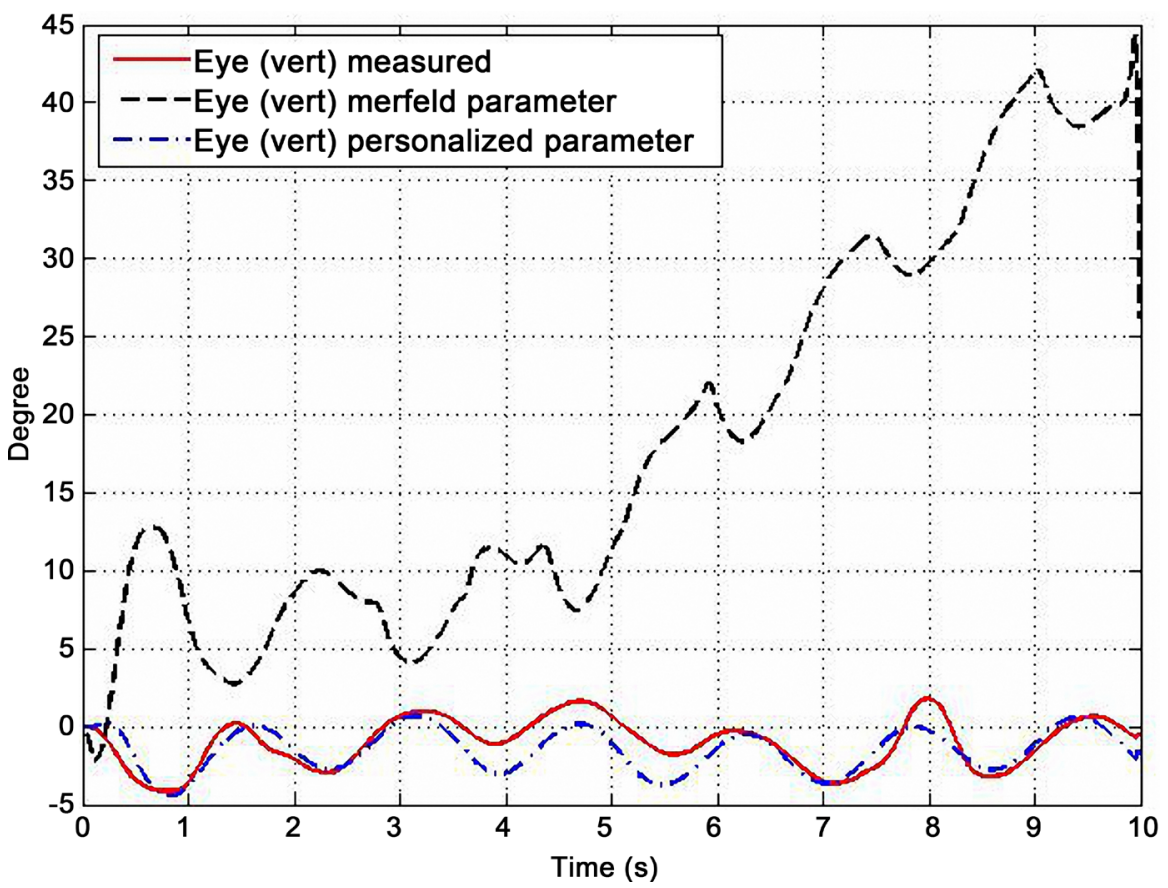

Figure 9. VOR parameter identification for Subject 3.

\subsection{Effect of the N-Back Task on Eye Movement with Changing Gaze Direction}

Figure 11 shows the original measurements and simulation results for Subject 2 in the absence of an additional mental workload (MWL) for a total of 83.8 seconds. The mean-square error for Subject 2 without an offset was 9.2E-03. 
Following Figure 11, the results of simulation show good matching especially in frequency and magnitude response. However, because of gaze change, the offset is necessary to apply.

On the basis of the time required to change the gaze direction, we created an offset value at a given time point by means of the following equation:

Offset(i) = average [measurement (start:stop)] - average [simulation (start:stop)]

After incorporation of the offset (Figure 12), the mean-square value for Subject 2 fell to $4.25 \mathrm{E}-04$.

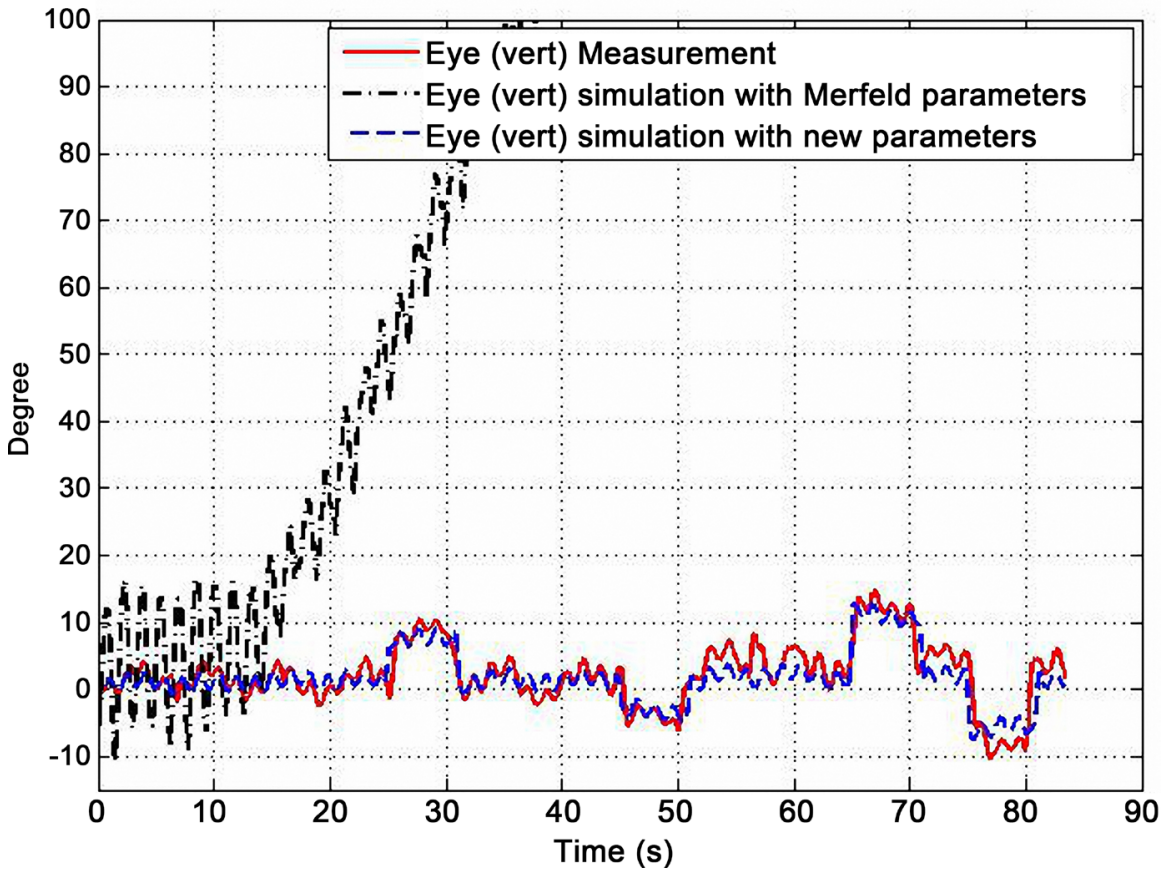

Figure 10. Eye movement in vertical axis of Subject 2.

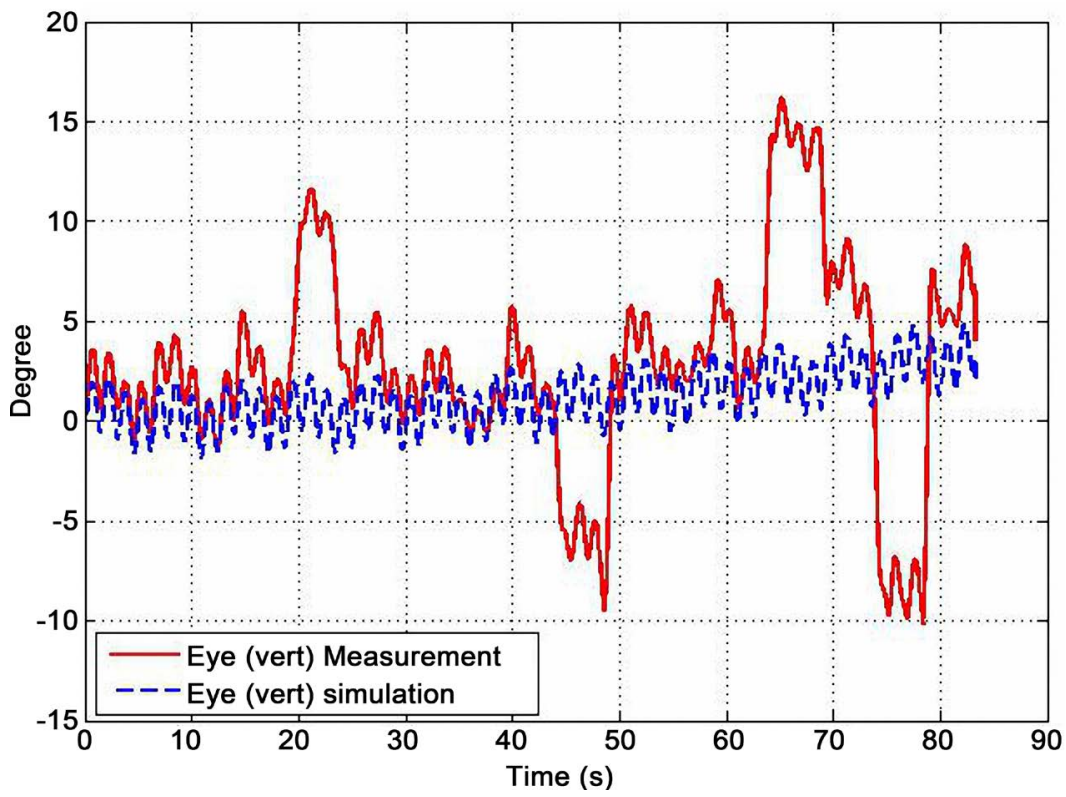

Figure 11. Simulated vertical eye movement without offset. 


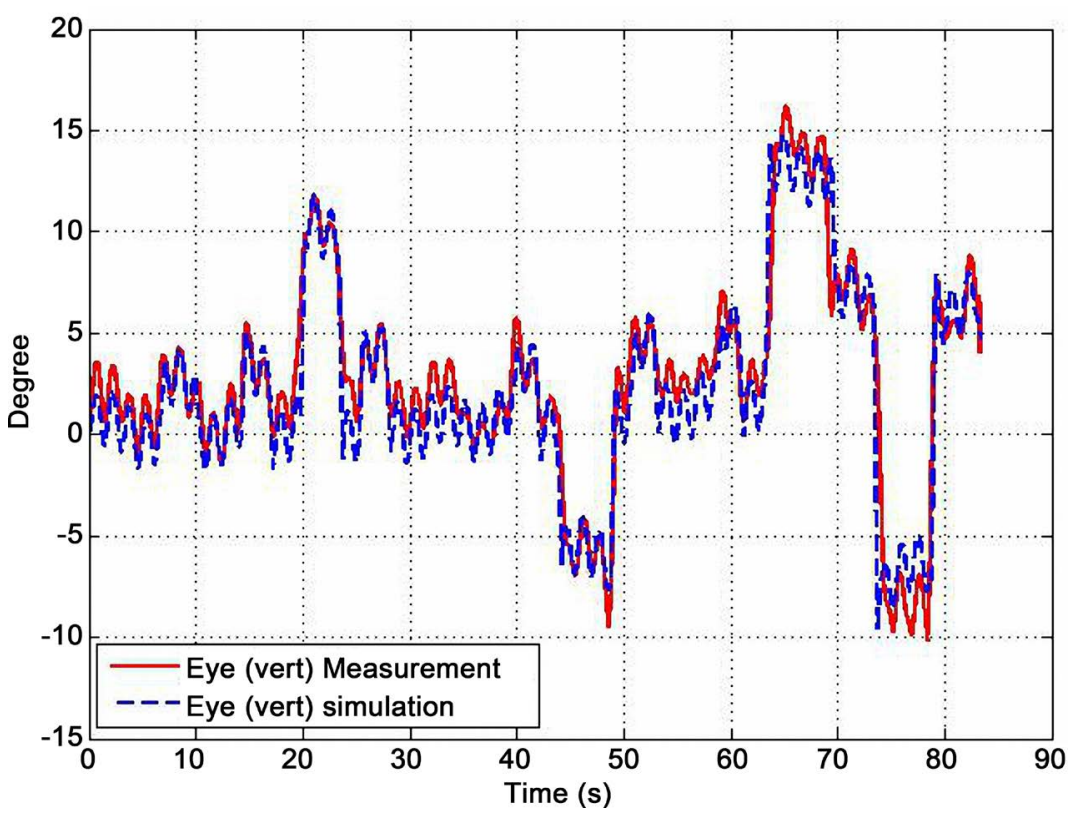

Figure 12. Vertical eye movement simulation with offset.

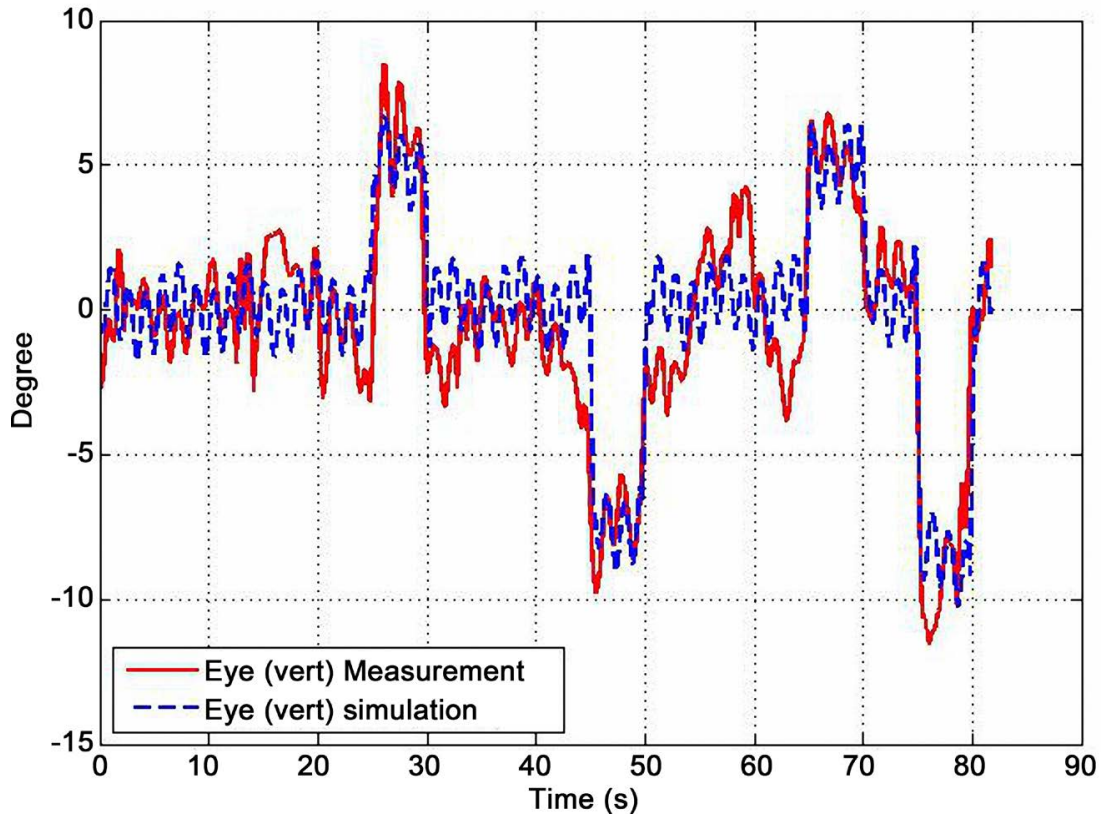

Figure 13. Vertical eye-movement simulation with a mental workload.

When an n-back task with a 1 s interval was used, a large difference was observed between the case with an MWL and that with no MWL. The mean-square error without an offset increased 1.33 times to 0.0123 . With an offset, it increased 2.83 times to 0.0012 . Figure 13 shows details of the simulation and results of measurement for this case.

With an MWL, the time and frequency response became mismatched. Consequently, the mean-square error increased compared with that in the absence of an MWL.

We conducted the same experiments for each participant with and without an 
MWL and we took the average of two trials for each subject; the details of the mean-square error are shown in Table 2.

Next, we performed an analysis of variance (ANOVA) for 30 trials of 15 subjects in the presence and absence of a mental workload, and with and without an offset with the following null hypothesis.

- The results with and without an offset are equal.

- The results in the presence and absence of a mental workload are equal.

- The results of Trial 1 and Trial 2 are equal.

The result of the ANOVA is shown in Table 3.

As expected, the effects of the offset and MWL were statistically significant ( $F$ $=142, p<0.001$, and $F=40.9, p<0.001$, respectively). The mean-square error in

Table 2. Mean-square error in the presence and absence of an MWL.

\begin{tabular}{ccccccc}
\hline \multirow{2}{*}{ Subject } & \multicolumn{2}{c}{ No MWL } & \multicolumn{2}{c}{ With MWL } & \multicolumn{2}{c}{ Ratio } \\
\cline { 2 - 7 } & No offset & Offset & No offset & Offset & No offset & Offset \\
\hline 1 & $9.00 \mathrm{E}-03$ & $1.01 \mathrm{E}-03$ & $9.25 \mathrm{E}-03$ & $2.85 \mathrm{E}-03$ & 1.03 & 2.81 \\
$\mathbf{2}$ & $4.65 \mathrm{E}-03$ & $1.35 \mathrm{E}-03$ & $9.50 \mathrm{E}-03$ & $6.15 \mathrm{E}-03$ & 2.04 & 4.56 \\
$\mathbf{3}$ & $5.45 \mathrm{E}-03$ & $1.55 \mathrm{E}-03$ & $7.70 \mathrm{E}-03$ & $4.60 \mathrm{E}-03$ & 1.41 & 2.97 \\
$\mathbf{4}$ & $6.25 \mathrm{E}-03$ & $1.65 \mathrm{E}-03$ & $1.09 \mathrm{E}-02$ & $5.20 \mathrm{E}-03$ & 1.74 & 3.15 \\
$\mathbf{5}$ & $6.10 \mathrm{E}-03$ & $1.10 \mathrm{E}-03$ & $7.10 \mathrm{E}-03$ & $2.00 \mathrm{E}-03$ & 1.16 & 1.82 \\
$\mathbf{6}$ & $6.30 \mathrm{E}-03$ & $1.30 \mathrm{E}-03$ & $9.30 \mathrm{E}-03$ & $4.70 \mathrm{E}-03$ & 1.48 & 3.62 \\
7 & $4.30 \mathrm{E}-03$ & $8.26 \mathrm{E}-04$ & $4.70 \mathrm{E}-03$ & $1.35 \mathrm{E}-03$ & 1.09 & 1.63 \\
$\mathbf{8}$ & $4.30 \mathrm{E}-03$ & $1.24 \mathrm{E}-03$ & $5.60 \mathrm{E}-03$ & $2.20 \mathrm{E}-03$ & 1.30 & 1.77 \\
9 & $4.70 \mathrm{E}-03$ & $1.55 \mathrm{E}-03$ & $6.60 \mathrm{E}-03$ & $3.05 \mathrm{E}-03$ & 1.40 & 1.97 \\
10 & $3.50 \mathrm{E}-03$ & $1.43 \mathrm{E}-03$ & $5.70 \mathrm{E}-03$ & $4.50 \mathrm{E}-03$ & 1.63 & 3.15 \\
11 & $4.55 \mathrm{E}-03$ & $1.55 \mathrm{E}-03$ & $4.95 \mathrm{E}-03$ & $2.50 \mathrm{E}-03$ & 1.09 & 1.61 \\
12 & $3.95 \mathrm{E}-03$ & $1.40 \mathrm{E}-03$ & $5.40 \mathrm{E}-03$ & $1.85 \mathrm{E}-03$ & 1.37 & 1.32 \\
13 & $7.30 \mathrm{E}-03$ & $4.30 \mathrm{E}-03$ & $1.25 \mathrm{E}-02$ & $5.45 \mathrm{E}-03$ & 1.71 & 1.27 \\
14 & $6.00 \mathrm{E}-03$ & $2.00 \mathrm{E}-03$ & $1.03 \mathrm{E}-02$ & $3.80 \mathrm{E}-03$ & 1.71 & 1.90 \\
15 & $3.40 \mathrm{E}-03$ & $1.14 \mathrm{E}-03$ & $5.60 \mathrm{E}-03$ & $4.20 \mathrm{E}-03$ & 1.65 & 3.68 \\
\hline
\end{tabular}

Table 3. ANOVA results.

\begin{tabular}{cccccr}
\hline & Df & Mean Sq. & F value & $\operatorname{Pr}(>\mathrm{F})$ & \\
\hline Offset & 1 & $4.73 \mathrm{E}-04$ & 142 & $2.00 \mathrm{E}-16$ & $* * *$ \\
MWL & 1 & $1.36 \mathrm{E}-04$ & 40.9 & $3.50 \mathrm{E}-09$ & $* * *$ \\
Trial & 1 & $2.1 \mathrm{E}-06$ & 0.643 & 0.424 & \\
Offset*MWL & 1 & $1.4 \mathrm{E}-06$ & 0.416 & 0.520 & \\
MWL*Trial & 1 & $7.60 \mathrm{E}-07$ & 0.103 & 0.749 & \\
Residuals & 116 & $3.3 \mathrm{E}-06$ & & &
\end{tabular}

${ }^{* *}: \mathrm{p}<0.001,{ }^{* *}: \mathrm{p}<0.01,{ }^{*}: \mathrm{p}<0.05$. Offset: a1: Without offset; a2: With offset; MWL: b1: No MWL; b2: With MWL; Trial: c1: Trial 1; c2: Trial 2. 


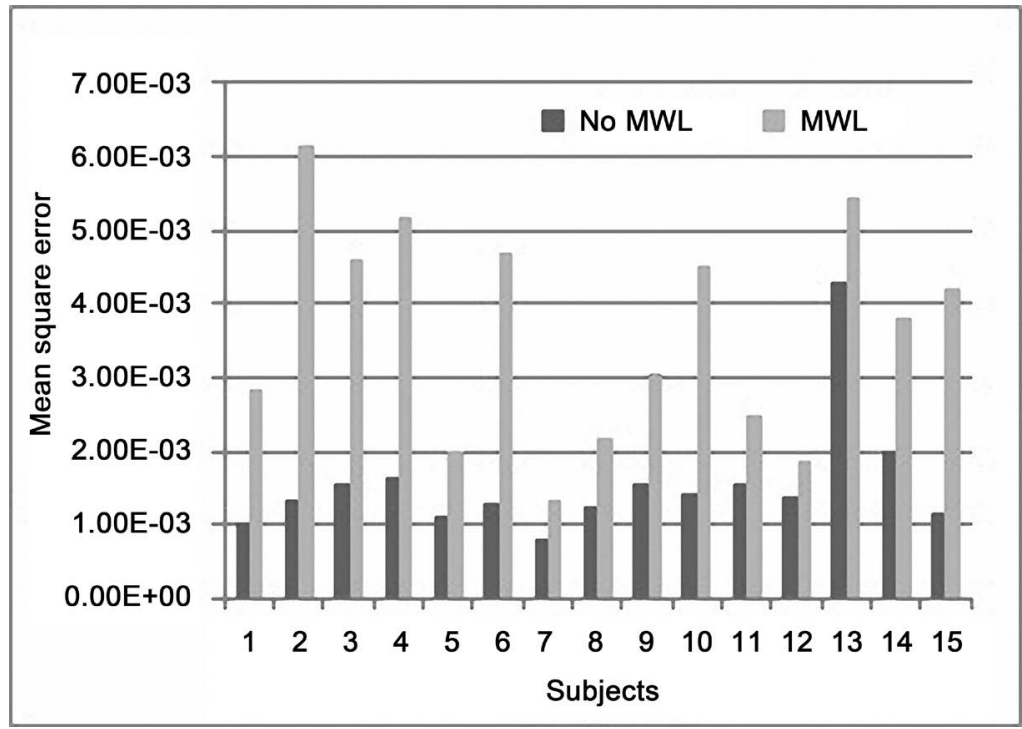

Figure 14. Average mean square error with offset for each subject.

the presence of an offset was significantly smaller than that in the absence of an offset, whereas that for no MWL was significantly smaller than that with a MWL. This shows that the method we have developed works well for evaluating MWL. There was no significant difference between the two trials and no interaction between the trial for MWL + offset and that with MWL only ( $p=0.424$ and 0.52 , respectively). This shows that our method can be used to evaluate driver distraction on the basis of the difference in mean-square error between the simulated eye movement and the measured values. The results are shown in more detail in Figure 14.

Our results showed a better performance than those previously obtained by Obinata and co-workers [3] [4] [11] [12]. The difference between the case with an MWL and that in its absence was clearer than the previous case, in which the average mean-square error for no MWL was $1.56 \mathrm{E}-03$ and that with an MWL was $3.48 \mathrm{E}-03$ (more than two times). On the other hand, in previous researches, the participants focused one fixed point and the computer controlled the seat movement. In our study, the subject changed their gaze throughout the study, which is much closer to actual behavior when driving.

\section{Summary/Conclusions}

These results confirm that our method can be applied in VOR experiments, and can be performed with a noninvasive sensor with a low mean-square error. In the near future, we hope to quantify in real time in a real vehicle. The distraction evaluation needed to combine the VOR model with optokinetic eye-movement response (OKR) models to determine the motions of the eyeball based on head movement and visual-scene movement.

The increase in the mean-square error in the presence of a demanding mental task implies that there is a relationship between the VOR mechanism and driver distraction. This result is consistent with those of previous studies by other re- 
searchers. On the other hand, our research produced a better performance with a lower mean-square error. With respect to applications pertaining to changes in gaze direction, we hope in the future that our technique will permit the successful application of VOR to the quantification of driver state for better cockpit design and development of driver-assistance systems.

Because of the limitation of subject, in the future, we will continue conducting the effect of driver cognitive distraction on eye movement not only in driving simulator but also actual vehicle to validate this method.

\section{Acknowledgements}

This research is in part supported by Toyota Motor Corporation. We are particularly grateful to Goro Obinata (Chibu University), Hiroto Hamada (Toyota Company), Kentaro Omura (Nagoya University), and their research group for providing us with secondary data, comments, and so on.

\section{References}

[1] Merfeld, D.M. and Zupan, L.H. (2002) Neural Processing of Gravitoinertial Cues in Humans. III. Modeling Tilt and Translation Responses. Journal of Neurophysiology, 87, 819-833.

[2] Robinson, D.A. (1981) The Use of Control Systems Analysis in the Neurophysiology of Eye Movements. Annual Review of Neuroscience, 4, 463-503. https://doi.org/10.1146/annurev.ne.04.030181.002335

[3] Obinata, G., Tokuda, S., Fukuda, K. and Hamada, H. (2009) Quantitative Evaluation of Mental Workload by Using Model of Involuntary Eye Movement. In: Harris, D., Ed., Engineering Psychology and Cognitive Ergonomics SE-24, Vol. 5639, Springer Berlin Heidelberg, 223-232. https://doi.org/10.1007/978-3-642-02728-4_24

[4] Obinata, G., Usui, T. and Shibata, N. (2008) On-Line Method for Evaluating Driver Distraction of Memory-Decision Workload Based on Dynamics of Vestibulo-Ocular Reflex. Review of Automotive Engineering, 29, 627-632.

[5] Munster, D. (2009) Parameter Identification: A Comparison of Methods.

[6] Goldberg, D.E. (1989) Genetic Algorithms in Search, Optimization, and Machine Learning. Addison-Wesley Longman Publishing Co. Inc., Boston, MA, USA.

[7] Pearl, J. (2001) Parameter Identication: A New Perspective (Second Draft). Introduction and Preliminary Terminology, 1, 1-19.

[8] Wang, G.S., Huang, F.K. and Lin, H.H. (2004) Application of Genetic Algorithm to Structural Dynamic Parameter Identification. 13th World Conference on Earthquake Engineering, Vancouver, 1-6 August 2004, Paper No. 3227.

[9] Petcu, F. and Leonida-Dragomir, T. (2010) Solar Cell Parameter Identification Using Genetic Algorithms. CEAI, 12, 30-37.

[10] Omura, K., Aoki, H. and Obinata, G. (2015) Objective Evaluation of the Brake Motion by Means of Passenger's Reflex Eye Movements. $13^{\text {th }}$ International Symposium on Advanced Vehicle Control, Munich, Germany.

[11] Usui, T., Obinata, G. and Shibata, N. (2007) On-Line Method for Evaluating the Driver Distractions of Memory-Decision Work Load Based on Dynamics of Vestibulo-Ocular Reflex. Proceedings of International Symposium on EcoTopia Science, 7, 1132-1136.

[12] Obinata, G., Tokuda, S. and Shibata, N. (2008) Mental Workloads Can Be Objec- 
tively Quantified in Real-Time Using VOR (Vestibulo-Ocular Reflex). IFAC Proceedings Volumes, 41, 15094-15099.

https://doi.org/10.3182/20080706-5-kr-1001.02553

[13] Kuczapski, A.M., Micea, M.V., Maniu, L.A. and Cretu, V.I. (2010) Efficient Generation of Near Optimal Initial Populations to Enhance Genetic Algorithms for JobShop Scheduling. Information Technology and Control, 39, 32-37.

[14] Koljonen, J. and Alander, J.T. (2006) Effects of Population Size and Relative Elitism on Optimization Speed and Reliability of Genetic Algorithms. Proceedings of the 9th Scandinavian Conference on Artificial Intelligence, Espoo, Finland, 54-60.

[15] Son, L.A., Aoki, H., Hamada, H. and Suzuki, T. (2015) Parameters Optimization Using Genetic Algorithm Technique for Vestibulo-Ocular Reflex Model. 3rd International Symposium on Future Active Safety Technology toward Zero Traffic Accidents, Gothenburg, Sweden, 9-11 September 2015, 167-174.

[16] Zupan, L.H. and Merfeld, D.M. (2003) Neural Processing of Gravito-Inertial Cues in Humans. IV. Influence of Visual Rotational Cues during Roll Optokinetic Stimuli. Journal of Neurophysiology, 89, 390-400. https://doi.org/10.1152/jn.00513.2001

[17] Green, A.M. and Angelaki, D.E. (2010) Internal Models and Neural Computation in the Vestibular System. Experimental Brain Research, 200, 197-222. https://doi.org/10.1007/s00221-009-2054-4

[18] Angelaki, D.E., Merfeld, D.M. and Hess, B.J.M. (2000) Low-Frequency Otolith and Semicircular Canal Interactions after Canal Inactivation. Experimental Brain Research, 132, 539-549. https://doi.org/10.1007/s002210000364

[19] Angelaki, D.E., Wei, M. and Merfeld, D.M. (2001) Vestibular Discrimination of Gravity and Translational Acceleration. Annals of the New York Academy of Sciences, 942, 114-127. https://doi.org/10.1111/j.1749-6632.2001.tb03739.x

Submit or recommend next manuscript to SCIRP and we will provide best service for you:

Accepting pre-submission inquiries through Email, Facebook, LinkedIn, Twitter, etc. A wide selection of journals (inclusive of 9 subjects, more than 200 journals)

Providing 24-hour high-quality service

User-friendly online submission system

Fair and swift peer-review system

Efficient typesetting and proofreading procedure

Display of the result of downloads and visits, as well as the number of cited articles

Maximum dissemination of your research work

Submit your manuscript at: http://papersubmission.scirp.org/

Orcontact jtts@scirp.org 